\title{
Effect of Socio-Demographic Characteristics on Kenyan Smallholder Dairy Farmers' Adaptive Strategies to Climate Change Effects
}

\author{
Charles Okech Odhiambo ${ }^{1 *}$, Chlirukovian Bwire Wasike ${ }^{2}$, Harun Okello Ogindo ${ }^{3}$ \\ ${ }^{1}$ Regreening Africa Project, World Vision Kenya, Nairobi, Kenya \\ ${ }^{2}$ Livestock Efficiency Enhancement Group (LEEG), Department of Animal Science, Maseno University, \\ Maseno, Kenya \\ ${ }^{3}$ Department of Applied Plant Science, Maseno University, Maseno, Kenya \\ Email: *charles_odhiambo@wvi.org
}

How to cite this paper: Odhiambo, C.O., Wasike, C.B. and Ogindo, H.O. (2019) Effect of Socio-Demographic Characteristics on Kenyan Smallholder Dairy Farmers' Adaptive Strategies to Climate Change Effects. Atmospheric and Climate Sciences, 9, 583599. https://doi.org/10.4236/acs.2019.94037

Received: August 1, 2019

Accepted: October 13, 2019

Published: October 16, 2019

Copyright $\odot 2019$ by author(s) and Scientific Research Publishing Inc. This work is licensed under the Creative Commons Attribution International License (CC BY 4.0).

http://creativecommons.org/licenses/by/4.0/

\begin{abstract}
Climate change (CC) impedes smallholder dairy industry in Kenya. Consequently, farmers' adaptation to CC effects would greatly determine their resilience, profitability, and sustainable contribution to the economy. Socio-demography among other factors, determine smallholder farmers' adaptive strategies to CC effects. This study sought to understand how smallholder dairy farmers in South Western Kenya adapt to climate changes and determine the relationship between famers' adaptive strategies and their socio-demographics of sex, age, marital status, highest educational level, household size, and experience in dairying. Concurrent Fixed Mixed Methods were used to collect primary and secondary data. Reports and papers were reviewed for temperature and precipitation data, dairy population, production trends, and farmers' socio-demographics. A survey questionnaire was administered to 367 smallholder dairy household heads with 10 years' experience obtained through multi-stage sampling of respondents from 4 sub counties of Migori county. The data collected included the respondents' socio-demographics, climate changes and adaptability to CC effects. Key informant interviews (KIIs) were conducted with heads of government departments of Livestock Production, Cooperative Development, Meteorology, Environment and Agriculture Sector Development Support Programme (ASDSP) in Migori County. Others included the leadership of Rongo Dairy Farmers' Cooperative Society, Lichota Livestock Development Farm, and a Research Officer for Livestock Production Systems with Kenya Agriculture and Livestock Research Organization (KALRO). Focus group discussions (FGDs), on the other hand, were conducted with old men and women (aged 60 years and above), and farmer
\end{abstract}


groups from Rongo Dairy Farmers Cooperative Society, Cham Gi Wadu Dairy and Multipurpose Cooperative Society, and East Sakwa Farmers' Development Group. These were obtained purposively based on dairying experience. Descriptive statistics (percentages) were used to describe climate change effect on smallholder dairying and farmers' adaptation. Percentages, minimum and maximum values, means, range, and standard deviations were used to describe respondents' socio-demographics. Binary logistic regression analysis was used to determine the effect of farmers' socio-demographics on their adaptive strategies to $\mathrm{CC}$ effects. Results indicated that individually, male farmers were more likely to adopt mixed crop and livestock farming (Odds $=3.97 ; \mathrm{p}=$ 0.02) and experience an increasing trend in income earning from milk sales (Odds $=0.63 ; \mathrm{p}=0.04)$. Individually, older farmers were significantly more likely to establish own fodder (Odds $=0.96 ; \mathrm{p}=0.03$ ), keep non-Friesians and their crosses (Odds $=0.97 ; \mathrm{p}=0.02$ ), and experience increasing trends in income earned from milk sales (odds $=1.02 ; \mathrm{p}=0.02$ ). Individually, household size significantly influenced establishment of own fodder (Odds $=0.69 ; \mathrm{p}=$ 0.00 ) and jointly with the other 5 socio-demographic factors (Odds $=0.70 ; \mathrm{p}=$ 0.00 ). With other socio-demographic factors, male farmers were more likely to rely mainly on household labour (Odds $=0.32 ; \mathrm{p}=0.05$ ). Thus, gender, age and household size were found to have significant effects on smallholder dairy farmers' adaptation to climate change effects in the study area.

\section{Keywords}

Smallholder Dairy Farmers, Southwestern Kenya, Climate Change

Adaptation, Socio-Demographic Factors, Adaptive Strategies

\section{Introduction}

Smallholder dairy systems are common in Sub-Saharan Africa, and are rapidly experiencing expansion due to urban growth and the subsequent increasing demand for milk, hence; opportunities to generate income [1]. Smallholder dairy farming in Kenya is practiced in mixed farming systems and contributes directly and indirectly to increased livestock population and farm productivity, income generation from milk and dairy product sales, job opportunities, and the transfer of money from urban to peri-urban and rural areas [2]. Nevertheless, the system faces challenges of over-reliance on informal milk market [3], high feed costs (up to $50 \%-60 \%$ of total production costs), and labour constraints [1]. There is also low level of investment by farmers to further improve the system, weak research-extension-farmer linkage, and ever-diminishing land sizes due to land sub-division as population continues to grow [1], as well as unpredictable weather patterns [4] and the animal genetics challenge to some extent [5]. Due to climate change, there is emergence of resistant strains of pests and diseases, and high pre- and post-harvest losses, leading to low financial returns on production [6]. It is for this matter that FAO recognizes "smallholder farmers" on the basis of 
their limited resource endowments relative to other farmers in the sector, and that the definition differs between countries and between agro-ecological zones [7].

A global trend observed in smallholder dairy production systems in most developing countries in recent decades due to climate change has been a significant change in patterns and quantities of rainfall, an increase in temperature, changes in winds, and changes in seasonality [8] [9]. There has also been more frequent catastrophic events; a decrease in feed and fodder production, reduced water availability, changing patterns and distribution of diseases, and changes in the marketing and price of commodities [8] [10]. Climate change in Africa has presented new challenges likely to erode much of the gains so far made with respect to food security, hampering rural development and livestock production [11]. Climate change will most likely lead to increased problems of water scarcity, shortage of pastureland and disease dynamics for smallholder dairy system [12]. These effects have forced most of the smallholder dairy farmers in several parts of the tropical world to resort to use of by-products or other wastes as feed, diversify production objectives to incorporate draught and meat production and increase levels of intensification [1].

In Kenya, global warming and the associated climate change is expected to exacerbate the challenge smallholder dairy farmers face, as there will be declining pasture and feed varieties, as well as decreased natural water sources with diminishing water quality [6]. The effects are expected to get even worse if business as usual scenario is maintained [8] [13], and would imply most of the Kenyan smallholder dairy farmers having challenges adapting and maintaining profitability [2] [12]. To cope with these effects, the Kenyan smallholder dairy farmers make efforts to increase levels of intensification, but which contributes further to global warming due to increased production of methane $\left(\mathrm{CH}_{4}\right)$, itself a greenhouse gas [2].

[14] indicate that technology-related factors, economic factors, physical factors, human factors, access to information and social network, credit systems, household-specific factors, cultural differences and travel costs are among the key factors that determine smallholder farmers' adoption of new agricultural technologies. The study sought to investigate the effects of socio-demographic characteristics of gender, age, marital status, educational level, household size and experience in dairying, on the adaptive strategies employed by smallholder dairy farmers of South Western Kenya to cope with climate change effects. Findings would be useful in providing advice to smallholder dairy farmers on appropriate adaptive strategies that take cognizance of their different socio-demographic profiles within the tropics.

\section{Materials and Methods}

\subsection{Study Site}

The study was conducted in Migori County, which is located in the Southwestern Kenya between latitude $0^{\circ} 24^{\prime}$ South and $0^{\circ} 40^{\prime}$ South and Longitude $34^{\circ}$ East 
and $34^{\circ} 50^{\prime}$ East. The County covers an area of $2596.5 \mathrm{~km}^{2}$ including approximately $478 \mathrm{~km}^{2}$ of water surface. The County comprises eight (8) sub-counties, namely: Rongo, Awendo, Uriri, Suna East, Suna West, Nyatike, Kuria West, and Kuria East. Four sub-counties namely Rongo, Awendo, Uriri, and Kuria West were selected for the study because they present a fairly homogenous climate, which also make them the dairy belt of the County. Within the four sub-counties, the study was confined to agro ecological zone $\mathrm{LM}_{3}$, except in Rongo, where it was undertaken in $\mathrm{UM}_{2}$.

Migori County has an inland equatorial climate modified by the effects of altitude, relief and Lake Victoria. Rainfall is generally continuous with little distinction between first and second rains. Annual rainfall averages between 700 $\mathrm{mm}$ and $1800 \mathrm{~mm}$ [15]. The first peak season comes over the months of March to May, and is reminiscent of the long rainy season; while the second peak season that is reminiscent of the short rains comes over the period of September-November. The two peaks are separated by a three month period each, of June-August and December-February. Precipitation received over the short rainy seasons in Migori County is on the increase, sometimes even being more reliable, well distributed and higher in amounts and spread (spatial and temporal) compared to the long rainy seasons [16]. On average February is considered the driest month, while April is the wettest month. Temperatures show mean minimum of $24^{\circ} \mathrm{C}$ and maximum of $31^{\circ} \mathrm{C}$, with a diurnal range of about $7^{\circ} \mathrm{C}$, relatively high humidity ranging between $40 \%$ and $95 \%$ (depending on season) and a potential evaporation of $1800 \mathrm{~mm}$ to $2000 \mathrm{~mm}$ per year.

In the four sub-counties of study, smallholder dairying is more prominent in Rongo, Awendo, Uriri and Kuria West. Although Kuria East and West present favourable climate for dairying, cattle rustling has remained a great impediment to the development of dairy industry [17].

The study site produced $26,441,643$ litres of milk in 2012, for a population of 917,170 people (2009 Census). Given that each person requires 1 cup (or $300 \mathrm{ml}$ ) of milk daily [18]; Migori County is generally a milk deficient county, having to subsidize its milk production with imports from neighbouring counties.

The county is predominantly into sugarcane production. However, in the four study sub-counties, smallholder dairy farming is rapidly gaining prominence. Land holdings among the smallholder dairy farmers in the study site is 3 acres on average, with the farmers practicing mixed crop and dairy farming. A mix of stall-feeding (mainly at night and during milking) and tethering of the dairy herd to graze within the homesteads, or in paddocks is common; with crop residues being used to substitute commercial feeds. Characteristically the smallholder dairy farmers of the study area keep cross-bred cattle, and depend largely on fodder from own farm, while a few lease land for fodder or buy fodder from neighbours. Most of the smallholders depend on water from the rivers, such as Kuja, Migori, Riana, Ongoche, and Sare. While some have sunk own shallow wells for watering the dairy cattle and for domestic use, others supplement with rain water harvesting (mainly in the form of roof catchment). The study was 
conducted only among the smallholder dairy farmers with at least 10 years' experience in dairying.

\subsection{Study Population and Sampling}

Secondary data obtained from Migori County Livestock Office indicated that the population of dairy farmers in the four sib-counties of study stood at 2528.

Yamanne's Formula [19] for small populations less than 10,000 was used to determine the sample size as follows:

$$
n=\frac{N}{1+N(e)^{2}}
$$

where:

$n=$ the desired sample size (for target populations less than 10,000);

$N=$ the population size;

$e=$ the level of precision or statistical significance set;

Therefore, given that the population of smallholder dairy farmers in the selected agro-ecological zones $\left(\mathrm{UM}_{2}\right.$ and $\left.\mathrm{LM}_{3}\right)$ of study within Migori County was 2528 , for measurement at $\mathrm{p}<0.05$, the desired sample size was:

$$
\begin{aligned}
n & =\frac{2528}{1+2528 \times(0.05)^{2}} \\
& =345.355(\approx 345 \text { smallholder dairy farmers })
\end{aligned}
$$

Adding $10 \%$ for non-respondents (i.e. $\approx 35$ ), the desired sample size for this study was 380 smallholder dairy farmers.

Due to difficulties in covering all the sampled households in parts of Kuria West, largely as a result of insecurity, the study was conducted among 367 smallholder dairy farmer households distributed among the four sub-counties as shown in Table 1.

Multi-stage sampling was used to obtain the sample. First, a visit was made to the sub-county livestock offices, from which a listing of all smallholder dairy farmers in each of the wards was obtained. Then, proportions of farmers in each of the wards were determined based on the populations listed. The same were used to distribute the required sample size within each of the wards.

Table 1. Sample size for the study.

\begin{tabular}{cccc}
\hline Sub-county & $\begin{array}{c}\text { Number of Smallholder } \\
\text { Dairy Farmers }\end{array}$ & Desired sample Size & Actual sample size \\
\hline Rongo & 1480 & 222 & 232 \\
Awendo & $\mathbf{8 8}$ & 13 & 13 \\
Uriri & 510 & 77 & 77 \\
Kuria West & 450 & 68 & 45 \\
Total & 2528 & 380 & 367 \\
\hline
\end{tabular}


Within each ward, the number of villages where smallholder dairying was being practiced was determined and proportionate random sampling was again used to assign the number of farmers per village. Within each village, simple random sampling was used to pick households for inclusion into the study.

On the other hand, for qualitative study, participants were identified and picked by purposive sampling, based on their role and level of involvement in smallholder dairying and meteorology.

\subsection{Data Collection}

Secondary data was obtained by review of reports and documents and from literature obtained from the internet, government offices and research stations (KALRO and Meteorological Department) using a data checklist. The data collected included the number of dairy cattle and smallholder dairy farmers in the four sub-counties of study, and their socio-demographic profiles. Other secondary data collected included temperature and precipitation data, as well as trends in milk production, demand and sales in the four sub-counties of study.

A structured household survey questionnaire was used to obtain primary data from heads of smallholder dairy households with at least 10 years' experience in dairying. The questionnaire solicited data on smallholder dairy farmers' socio-demographics (gender, age, marital status, highest educational level, household size, and experience in dairying); and adaptive strategies to climate change effects (farming type adopted, production method employed, major source of fodder, breed types kept, specific dairy breeds kept, main source of farm labour, trend in income from dairying over the past ten years). On the other hand, key informant interview (KII) and focus group discussion (FGD) guides were used to collect primary qualitative data from individuals and groups perceived to be experts and opinion leaders on climate change.

Key informants included heads of key government parastatals and departments (of meteorology, environment, livestock production, cooperatives, and Lichota Livestock Development Farm, leadership of Rongo Dairy Farmers' Cooperative Society, and a Research Officer for Livestock Production Systems with Kenya Agriculture and Livestock Research Organization (KALRO)-Kisii Station.

Focus group discussions were conducted with community elders (men and women) aged over 60; members of Rongo Dairy Farmers' Cooperative Society, Cham Gi Wadu Dairy and Multipurpose Cooperative Society and East Sakwa Farmers' Development Group and proceedings recorded using a digital recorder. Transcription was done verbatim after listening to the recordings several times. A research note book was only used to note cues for reference.

In addition, Non-participant Observation, farm visits and transect walks were used to collect additional information for the study and were useful in providing further insights on gender roles in smallholder dairy industry in the study site. An observation guide was prepared and used to facilitate the recording of information. The information was collected using a camera, recorder, and by 
note-taking.

\subsection{Data Analysis}

Socio-demographic factors were analysed using descriptive statistics, including percentages, minimum and maximum values, means, range and standard deviation. Binary logistic regression analysis was then undertaken to show whether there was any relationships between smallholder dairy farmers' socio-demographic characteristics and their adaptive strategies to climate change effects, and whether the relationships were significant.

Each of the 8 measures of adaptation to climate change effects was run against each of the six (6) socio-demographic characteristics singly and then jointly; with findings being presented at $\mathrm{p}<0.05$.

The general regression equation in this case models the log odds of a binary outcome, $y$ (adaptive strategy) as a function of predictor $x$ (smallholder farmers' socio-demographics) and is given as:

$$
\ln =\left[\frac{p}{1-p}\right]=\beta_{0}+\beta_{1} x_{1}+\beta_{2} x_{2}+\cdots+\beta_{6} x_{6}
$$

where:

$$
p=\text { proportion (probability) of } y=1 \text {, and }
$$

$x_{1}-x_{6}=$ the predictor socio-demographic characteristics of sex, age, marital status, highest educational level, household size, and experience in dairy farming.

$\beta_{0}=$ The $\log$ odds of a smallholder dairy farmer being perceived to be an adopter of adaptive strategies to climate change effects (when $x_{i}=0$ ) and

$\beta_{1-6}=$ The $\log$ odds of a smallholder dairy farmer being perceived to be an adopter of adaptive strategies to climate change effects (when $x_{i}=1-6$ ).

Results were, therefore, a presentation of the odds ratio of the significant relationships between socio-demographic factors of smallholder dairy farmers and their adaptive strategies to the effects of climate change in the study area.

Qualitative data (KIIs and FGDs) was first transcribed from the voice recordings into word. The word version was then entered into an excel spreadsheet and analysed using the Framework Approach. The data was first summarized into six themes on the basis of the six socio-demographic characteristics, relating each of these to the eight adaptive strategies. This produced a robust matrix that would then allow for sifting and sorting of the data to fit the desired thematic root of analysis, bearing in mind that each of the six socio-demographic characteristics had the potential of appearing eight times in the analysis matrix. Indexes were used to help in the sorting, while charts (or quotes) related to particular thematic routes of analysis were grouped together to form a clear map that could then allow for logical interpretation of the findings. This enabled the researcher to relate each of the six socio-demographic characteristics to the adaptive strategies smallholder dairy farmers used to cope with effects of climate change. 


\section{Results}

\subsection{Socio-Demographic Profile of Study Respondents}

The study established that $62.7 \%$ of the respondents were males, while $37.3 \%$ were females. Majority $(89.4 \%)$ of the study respondents were married, $9.0 \%$ were widows, $0.8 \%$ were widowers; while $0.3 \%$ were separated. Only $0.5 \%$ of the study respondents were single, as shown in Figure 1.

The mean age of the respondents was 50.69 years, with a minimum of 20 years and a maximum of 85 years $(S D=11.86)$. As shown in Figure 2, the proportion of respondents that completed Primary School was the same as that which completed Secondary Education, being 21.3\% each. 12.3\% of the respondents went to Secondary School, but did not complete Secondary Education. Some 3\% of the respondents had attained first degree, with $10.4 \%$ having attained Certificate Level of Education.

The mean household size was 6.23, with a minimum of 1 and a maximum of $15(\mathrm{SD}=2.52)$. The mean level of experience in smallholder dairy farming that the respondents had was 15.66 years, with a minimum of 10 years and a maximum of 38 years $(S D=5.60)$. The average land size was established to be 4.01 acres, with a minimum of 0.5 acres and a maximum of 83.5 acres $(\mathrm{SD}=4.74)$.

\subsection{Influence of Socio-Demographics on Farmers' Adoption of Climate Change Adaptive Strategies}

[20] established that climate changes have taken place over a 30-year period within the study area; with respect to increases in temperatures and precipitation; to the extent that comparing the 1960 s and 70 's, both day and night temperatures used to be colder than today. As from late 70's and early 80 's, there has been a remarkable increase in day and night temperatures; with the increase being very steady and presenting a direct proportionality with time, more so since

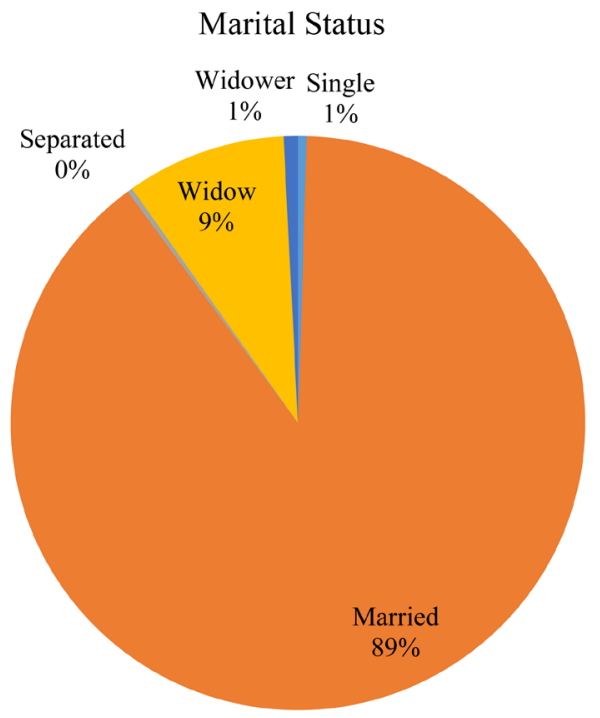

Figure 1. Distribution of respondents by marital status. 


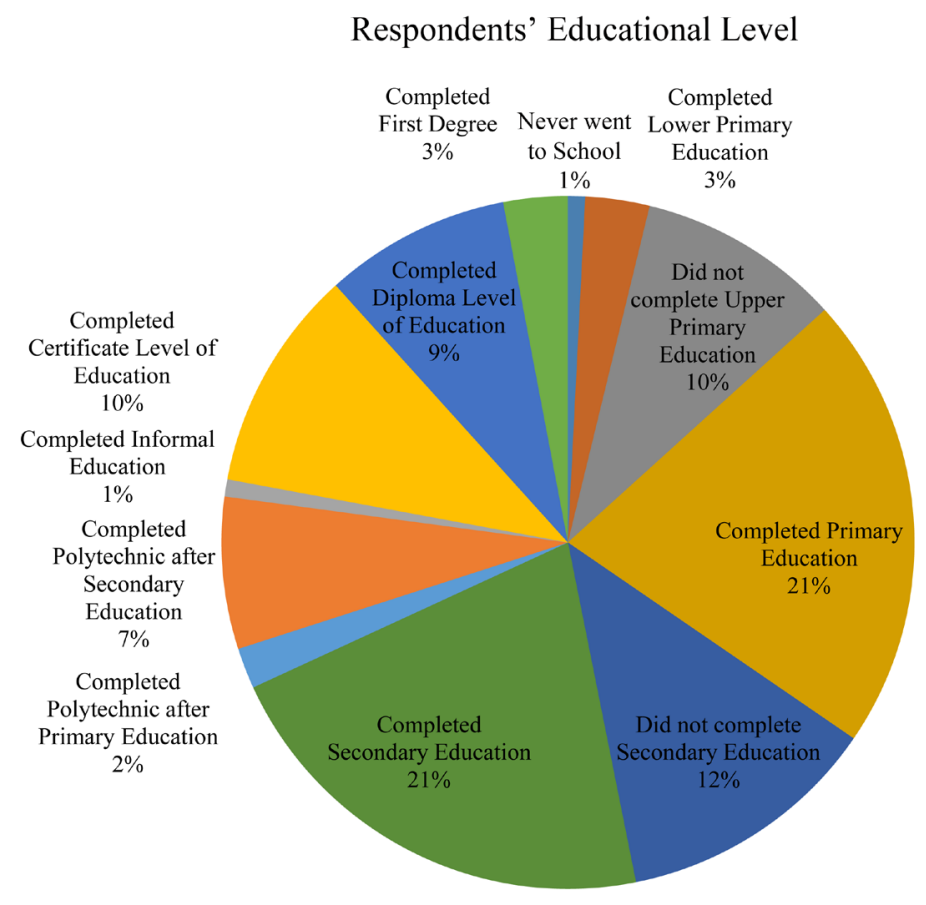

Figure 2. Distribution of respondents by highest level of education.

the year 2000. On the other hand, total amount of rainfall has more or less remained constant, comparing the 60's and today; with notable changes being observed with respect to rainfall patterns (seasonality, distribution, onset, duration, and frequency).

In the same study, [20] established that the changes in temperature and precipitation observed in Southwestern Kenya have had moderate to high impact on the smallholder dairy industry in the study area. Thus, respondents indicated that climate changes have led to increases in labour demand $(42.2 \% ; n=367)$; decrease in milk quality $(41.1 \% ; \mathrm{n}=367)$; decline in milk production $(38.7 \% ; \mathrm{n}=$ $367)$; drying of nearest water sources $(37.1 \% ; n=367)$; scarcity of water $(36.8 \%$; $\mathrm{n}=367)$; and loss of livestock ( $35.1 \% ; \mathrm{n}=367)$. These have all had a moderate effect on smallholder dairy industry in the study area. On the other hand, increase in diseases and pests $(61.0 \% ; \mathrm{n}=367)$; loss of pasture $(42.2 \% ; \mathrm{n}=367)$; over grazing of land $(41.1 \% ; n=367)$; and under feeding of livestock $(39.5 \% ; n=$ 367), all have had high impacts on the smallholder dairy industry in the study area.

Moreover, the study by [20] further found out that smallholder dairy farmers in the study area adapt to the changes in climate by practicing mixed farming, non-intensive dairying, establishing own fodder, rearing crossbred cattle, reducing dairy herd size to 2 , relying mainly on household labour, and maintaining a 10-year increasing trend in milk-income.

In this study, the respondents' socio-demographic characteristics with significant effects on the smallholder farmers' adaptive strategies to climate change effects are presented in Table 2. 
Table 2. Relationships between Socio-demographic factors and smallholder dairy farmers' adaptive strategies to climate change effects.

\begin{tabular}{|c|c|c|c|c|c|c|c|c|c|c|c|c|c|c|c|c|c|c|}
\hline \multirow{4}{*}{$\begin{array}{l}\text { Adaptive } \\
\text { Strategies }\end{array}$} & \multicolumn{18}{|c|}{ Socio-demographic Factors } \\
\hline & \multicolumn{6}{|c|}{ Gender (Male) } & \multicolumn{6}{|c|}{ Age } & \multicolumn{6}{|c|}{ Household Size } \\
\hline & \multicolumn{3}{|c|}{$\begin{array}{l}\text { Crude Odds } \\
\text { (95\% C.I) }\end{array}$} & \multicolumn{3}{|c|}{$\begin{array}{l}\text { Adjusted Odds } \\
\text { (95\% C.I) }\end{array}$} & \multicolumn{3}{|c|}{$\begin{array}{l}\text { Crude Odds } \\
\text { (95\% C.I) }\end{array}$} & \multicolumn{3}{|c|}{$\begin{array}{l}\text { Adjusted Odds } \\
\text { (95\% C.I) }\end{array}$} & \multicolumn{3}{|c|}{$\begin{array}{l}\text { Crude Odds } \\
\text { (95\% C.I) }\end{array}$} & \multicolumn{3}{|c|}{$\begin{array}{l}\text { Adjusted Odds } \\
\quad(95 \% \text { C.I })\end{array}$} \\
\hline & $\frac{8}{0}$ & $\vec{ن}$ & 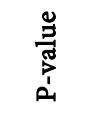 & $\frac{8}{0}$ & $\vec{ن}$ & 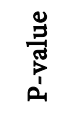 & $\vec{z}$ & $\vec{ن}$ & 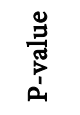 & $\overrightarrow{0}$ & $\vec{ن}$ & 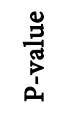 & $\frac{8}{0}$ & $\vec{ن}$ & 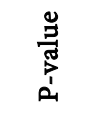 & $\pi_{0}^{0}$ & $\vec{ن}$ & 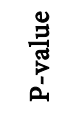 \\
\hline \multirow{3}{*}{$\begin{array}{c}\text { Farming } \\
\text { Type }\end{array}$} & & 1.2 & & & 0.14 & & & & & & & & & & & & & \\
\hline & 3.97 & - & $0.02^{*}$ & 0.63 & - & 0.55 & & & & & & & & & & & & \\
\hline & & 13.2 & & & 2.89 & & & & & & & & & & & & & \\
\hline & & & & & & & \multicolumn{3}{|c|}{0.93} & \multicolumn{3}{|c|}{0.94} & \multicolumn{3}{|c|}{0.56} & \multicolumn{3}{|c|}{0.55} \\
\hline $\begin{array}{l}\text { Own } \\
\text { Fodder }\end{array}$ & & & & & & & 0.96 & $\begin{array}{c}- \\
1.00\end{array}$ & $0.03^{*}$ & 0.98 & $\begin{array}{c}- \\
1.02\end{array}$ & 0.26 & 0.69 & $\begin{array}{c}- \\
0.85\end{array}$ & $0.00^{*}$ & 0.70 & $\begin{array}{c}- \\
0.88\end{array}$ & $0.00^{*}$ \\
\hline & & & & & & & & 0.94 & & & 0.95 & & & & & & & \\
\hline $\begin{array}{c}\text { Breeds } \\
\text { kept }\end{array}$ & & & & & & & 0.97 & $\begin{array}{c}- \\
1.00\end{array}$ & $0.02^{*}$ & 0.98 & $\begin{array}{c}- \\
1.02\end{array}$ & 0.38 & & & & & & \\
\hline Farm & & 0.23 & & & 0.10 & & & & & & & & & & & & & \\
\hline labour & 0.58 & - & 0.23 & 0.32 & - & $0.05^{*}$ & & & & & & & & & & & & \\
\hline source & & 1.42 & & & 1.00 & & & & & & & & & & & & & \\
\hline Dairy & & 0.40 & & & 0.68 & & & 1.00 & & & 1.02 & & & & & & & \\
\hline income & 0.63 & - & $0.04^{*}$ & 1.23 & - & 0.49 & 1.02 & - & $0.02^{*}$ & 1.04 & - & $\mathrm{n} / \mathrm{a}$ & & & & & & \\
\hline trend & & 0.99 & & & 2.23 & & & 1.04 & & & 1.07 & & & & & & & \\
\hline
\end{tabular}

Individually, gender significantly influenced $(\mathrm{p}<0.05)$ the choice of farming type adopted (Odds $=3.97 ; \mathrm{p}=0.02$ ), realization of an increasing trend in income from milk sales (Odds $=0.63 ; \mathrm{p}=0.04$ ), but these were both insignificant when jointly considered alongside other socio-demographic factors (Odds = $0.63 ; \mathrm{p}=0.55)$ and (Odds $=1.23 ; \mathrm{p}=0.49$ ), respectively. However, when all other socio-demographic factors were jointly considered, gender was found to have a significant influence on choice of the main source of farm labour (Odds = $0.32 ; \mathrm{p}=0.05)$.

Respondents' age individually significantly influenced the practice of establishing own fodder (Odds $=0.96 ; \mathrm{p}=0.03$ ), the type of breeds kept (Odds $=0.97$; $\mathrm{p}=0.02$ ), and realization of an increasing trend in income from milk sales (Odds $=1.02 ; \mathrm{p}=0.02)$. However, when all the other socio-demographic factors were considered jointly, the influence of age on adoption of the own fodder (Odds $=0.98 ; \mathrm{p}=0.26)$, breed types kept (Odds $=0.98 ; \mathrm{p}=0.38)$ and realization of an increasing trend in income from milk sales (Odds $=1.23 ; \mathrm{p}=0.49$ ) were insignificant. Nevertheless, age significantly influenced the realization of an increasing trend in income from milk sales among the study respondents (Odds = $1.04 ; \mathrm{p}=\mathrm{n} / \mathrm{a})$.

The study established that household size significantly influenced the establishment of own fodder, both individually (Odds $=0.69 ; \mathrm{p}=0.00)$ and jointly 
with the other 5 socio-demographic factors (Odds $=0.70 ; \mathrm{p}=0.00)$.

\section{Discussions}

Effects of Socio-demographic characteristics on Smallholder Diary Farmers; Adaptive Strategies to Climate Change Effects.

\subsection{Gender}

Although independently being male significantly influenced the farming type adopted and realization of an increasing trend in income from milk sales, when all the socio-demographic factors were jointly considered, this influence was found to be insignificant. This finding implies that gender could be a predictor of adoption of mixed crop-livestock farming systems. This is consistent with that by [13] [21] [22] and [23] that gender of household head did not significantly affect technology adoption. Yet the findings contradict those of [24] [25] [26] and [27], who found gender to significantly influence technology adoption [28]. found that gender of household head, among other factors, significantly influenced adoption of house-related adaptation strategies to climate change effects.

From the study findings, gender could predict realization of an increasing trend in income from milk sales (Odds $=0.63 ; \mathrm{p}=0.04$ ), such that male farmers would be more likely to realize this trend compared to their female counterparts, but many factors come into play for this rend to be realized by smallholder farmers.

When considered jointly with the other five socio-demographic factors, the household head's gender significantly influenced the choice of the main source of farm labour, hence; male farmers were more likely to rely on household labour than female farmers by a factor of about 0.32 (Odds $=0.32 ; \mathrm{p}=0.05$ ) compared to their female counterparts. These findings are similar to those by [29] and [30].

The differences in adaptive strategies practiced by males and females could be explained by differences in their values and worldviews. [31] argued that males are generally more aggressive and could easily accept to try new things than females. This could explain why males practiced mixed crop-dairy farming compared to females. Nevertheless, when age, marital status, educational level, household size, and experience in dairy farming are considered jointly with gender, this effect becomes insignificant. This indicates that many factors influence smallholder farmers' choice of adaptive strategy to climate change.

On the other hand, married, educated, and more experienced female farmers would be expected to be more engaged in productive activities, and hence; would tend to hire extra labour during the peak periods than relying solely on household labour. Again, this is largely determined by the world views of such women farmers.

\subsection{Age}

Individually, older farmers were found to be more likely to establish own fodder 
for the smallholder dairy enterprise (Odds $=0.96 ; \mathrm{p}=0.03$ ), keep non-Friesian breeds and their crosses (Odds $=0.97 ; \mathrm{p}=0.02$ ), and experience increasing trend in income from milk sales (Odds $=1.02 ; \mathrm{p}=0.02)$ viz a vis younger farmers. Nevertheless, only the influence on realization of increasing trend in income from milk sales was significant when jointly considered (Odds $=1.02 ; \mathrm{p}=0.02$ ). This implies that age could predict adoption of own fodder, such that older farmers were more likely to adopt the practice by a factor of about 0.96 compared to younger ones. Age could also predict the adoption of rearing of adaptable non-Friesian breeds and their crosses, such that older farmers were more likely to rear such breeds by a factor of about 0.97 compared to their younger counterparts. Nevertheless, age significantly influences realization of an increasing trend in income from milk sales, with older farmers more likely to realize this trend by a factor of 1.04 . These findings could be explained by the fact that with age comes the much needed experience [32], and would point to the fact that such older farmers adopt the practice of establishing own fodder and rearing non-Friesian breeds and their crosses out of exposure to the shock associated with droughts and the resultant feed shortages [27]. Such farmers also know how to adjust milk prices over time to ensure they remain in production, hence; experience increasing trends in income from milk sales. Nevertheless, such old farmers would be reluctant to try new technologies [33]. This is consistent with findings from several studies [23] [26] [31] [32] [34] [35] [36] [37] [38] and, but contradicts that by [39]; who found that young farmers were more likely to adapt to climate change effects than older farmers. [28] while assessing climate change adaptation strategies used by smallholder livestock farmers in Upper West Region of Ghana, found that farmers' age, among other factors influenced the adoption level of feed-related, breed-related, and health-related adaptation strategies to climate change effects. [21] on the other hand, found age to have no significant relationship with adaptation of tea farmers to climate change.

[13], moreover, suggested that there is mixed influence of age on the skills that farmers employ to adapt to climate change, and to adopt new technologies. This could explain why when the other five socio-demographic factors were jointly considered with age, the influence in each case became insignificant, and household size was now the one that significantly influenced the establishment of own fodder by the study respondents. This indicates that although age is critical in determining adoption of climate change adaptive practices, probably other farmer attributes and economic factors play a more critical role.

\subsection{Marital Status}

Respondents' marital status was found never to influence climate change adaptation by smallholder framers, whether individually or jointly with the other five socio-demographic factors. Although some studies have indicated that married farmers are more stable, made joint decisions regarding their farming business, and shared resources, hence; influenced technology adoption in agriculture [38] [40] and [41]; a number of other studies [42] [43] do not seem to indicate that 
marital status plays any significant role in technology adoption. Thus, more studies need to be undertaken to clearly understand the influence of marital status on agricultural technology adoption.

\subsection{Educational Level}

Respondents' level of education was found never to influence climate change adaptation by smallholder framers whether individually or jointly with the other five socio-demographic factors. This contradicts findings from several studies [13] [23] [26] [29] [32] [34] [35] [38] [44] [45]. [38] even found the number of adaptive practices adopted by farmers to be positively associated with education, among others.

Generally, education is perceived to play an important role in influencing the farmer's decision to adopt a new technology. In this respect, the farmer's level of education would be understood to increase his/her ability to obtain; process and use information related to the adoption of the new technology [30].

Thus, the findings that smallholder farmers' education level had no significant influence on their adoption of climate change adaptive strategies is one of those rare ones. Nevertheless, it could be explained from two perspectives-first the fact that the farmers gained much information from the mass media, and secondly, that the farmers depended a lot on peer influence for them to adopt new technologies relating to climate change adaptation.

\subsection{Household Size}

Both individually and jointly, household size significantly influenced adoption of Own Fodder adaptive strategy to climate change. This is similar to that by several studies that indicate that farmers with large household sizes tend to take up more labour intensive technologies compared to those with small household sizes [9] [13] [23] [29] [39]. The significant role played by household size in climate change adaptation is well demonstrated by [38], who found the number of adaptive strategies being practiced by farmers in Pakistan to be positively associated with household size, level of education, being male, land size, access to extension services and credit, as well as wealth.

\subsection{Experience in Dairy Farming}

The smallholder dairy farmers' experience in dairying had no significant influence on the adoption of climate change adaptation strategies. Although this contradicts findings from several studies [13] [21] [28] [31] [46], it could be explained by the fact that all the study respondents had been stratified by virtue of the fact that they had an experience of at least 10 years in dairy farming. Thus, had the dairy farmers in the study area been randomly selected, the effect of experience in the practice would have had a significant effect in climate change adaptation.

\section{Conclusions}

Male farmers were found to be more likely to practice mixed farming, use family 
labour for farm operations, and realize increased trend in income from milk sales. On the other hand, older farmers were more likely to establish own fodder, rear non-Friesian dairy cattle and their crosses, and experience increased trend in income from milk sales.

Marital status, educational level, and experience in dairy farming did not have any significant influence on Migori smallholder dairy farmers' adaptation to climate change effects.

Being a patriarchal society, gender, age and household size are very strong predictors, and significantly influence smallholder dairy farmers' adoption of climate change adaptive strategies. Thus, older, male headed households with large family sizes are better adapted compared to the young, female-headed households with smaller household sizes.

Thus, governments and stakeholders should consider supporting young, female-headed households with smaller household sizes in order to improve their adaptive capacities to climate change effects. Appropriate extension messages targeting such farmers, especially in rural patriarchal societies should be developed and disseminated using appropriate farmer-focused participatory approaches.

\section{Acknowledgements}

We are grateful to Migori County Livestock Office for invaluable support during preliminary visits, sampling, and providing secondary data relating to the performance of the smallholder dairy industry in the County and the potential for improvement. We are also indebted to the Meteorological Department-Migori County and KALRO-Kisii for support with secondary data on climate changes and adaptive practices that smallholder dairy farmers adopt in Migori County and the region.

\section{Conflicts of Interest}

The authors declare no conflicts of interest regarding the publication of this paper.

\section{References}

[1] Moran, J. (2005) Tropical Dairy Farming: Feeding Management for Smallholder Dairy Farmers in the Humid Tropics. Landlinks Press, Collingwood, Victoria, Australia, 312 pp. https://doi.org/10.1071/9780643093133

[2] Bebe, B.O. (2003) Herd Dynamics of Smallholder Dairy in Kenya Highlands. Published Ph.D. Thesis. Wageningen Agricultural University, The Netherlands.

[3] Omore, A.O., McDermott, J.J.S. Arimi, S.M. and Kang'ethe, E.K. (2000) Analysis of Public Health Risks from Consumption of Informally Marketed Milk in Kenya. Paper Presented at the Faculty of Veterinary Medicine Biennial Scientific Conference, Nairobi, Kenya.

[4] Kenya Agribusiness and Agroindustry Alliance (2016) Challenges Facing Smallholder Dairy Farmers in Kenya. 
[5] Muriuki, H.G. (2003) A Review of the Small Scale Dairy Sector-Kenya. Milk and Dairy Products, Post-Harvest Losses and Food Safety in Sub-Saharan Africa and the Near East. FAO Prevention of Food Losses Programme. FAO, Rome.

[6] Huho, J.M., Ngaira, K.W., Ogindo, H.O. and Masayi, N. (2012) The Changing Rainfall Pattern and the Associated Impacts on Subsistence Agriculture in Laikipia East District, Kenya. Journal of Geography and Regional Planning, 5, 198-206.

[7] FAO (1997) Food and Agriculture Organisation of the United Nations. Report on the 1990 World Census of Agriculture: International Comparison and Primary Results by Country (1886-1995), Statistical Development Series 9, FAO. Rome.

[8] ICARDA/CCAFS (2012) Strategies for Combating Climate Change in Drylands Agriculture. Synthesis of Dialogues and Evidence Presented at the International Conference on Food Security in Dry Lands, Doha, Qatar.

[9] Kirui, J.W. (2014) Assessment of the Influence of Climate Change on Smallholder Dairy Productivity in Kosirai, Kenya and Namayumba in Uganda. University of Nairobi. Kenya.

[10] Ngare, I.O. (2017) Farmers' Perceptions on the Effects of Climate Change Variability on Dairy Farming in Masaba North, Nyamira County, Kenya. Kenyatta University, Kenya.

[11] Ojango, J.M.K., Wasike, C.B., Enahoro, D.K. and Okeyo, A.M. (2016) Dairy Production Systems and the Adoption of Genetic and Breeding Technologies in Tanzania, Kenya, India and Nicaragua. Animal Genetic Resources, 59, 81-95.

[12] Tadesse, G. and Dereje, M. (2018) Impact of Climate Change on Smallholder Dairy Production and Coping Mechanism in Sub-Saharan Africa-Review. Agricultural Research \& Technology, 16, Article No. 556000. https://doi.org/10.19080/ARTOAJ.2018.16.556000

[13] Hassan, R. and Nhemachena, C. (2008) Determinants of African Farmers' Strategies for Adapting to Climate Change: Multinomial Choice Analysis. African Journal of Agricultural Research and Extension, 2, 83-104.

[14] Obayelu, A.E., Ajayi, O.D., Oluwalana, E.O.A. and Ogunmola O.O. (2017) What Does Literature Say About the Determinants of Adoption of Agricultural Technologies by Smallholders Farmers? Agricultural Research \& Technology: Open Access Journal, 6, Article No. 555676. https://doi.org/10.19080/ARTOAJ.2017.06.555676

[15] GoK (2013a) Brief of Migori County. Agriculture Sector Development Support Programme (ASDSP) Migori, Kenya.

[16] UNDP (2012) United Nations Development Programme. Climate Risk Management Report, November 2012. Climate Risks, Vulnerability and Governance in Kenya: A Review.

[17] GoK (2013) Migori County Integrated Development Plan, 2013-2017. Government of Kenya. Nairobi, Kenya.

[18] NebGuide (2012) My Plate: Dairy Group. University of Nebraska-Lincoln Extension. Institute of Agriculture and Natural Resources. G1611. IANR. University of Nebraska, Linkoln, NE.

[19] Taro, Y. (1967) Statistics: An Introductory Analysis. 2nd Edition, Harper and Row, New York.

[20] Odhiambo, C.O., Ogindo, H.O., Wasike, C.B. and Ochola, W.O. (2019) Adaptation of Smallholder Dairy Farmers in South Western Kenya to the Effects of Climate Change. Atmospheric and Climate Sciences, 9, 456-478.

https://doi.org/10.4236/acs.2019.93031 
[21] Limo, W.K. (2013) Factors Influencing Climate Change Adaption among Tea Farmers in Chebut Catchment Area of Nandi Central District, Kenya. Research Project Report for M.A. in Project Planning and Management, University of Nairobi, Nairobi, Kenya.

[22] Odhiambo, C. (2014) Factors Affecting Adoption of Crossbred Goat by Migori Farmers, Kenya. LAP Lambert Academic Publishing, Saarbrucken, Germany.

[23] Amuge, M.L. and Osewe, D.O. (2017) Socio-Economic Factors Influencing Adoption of Feed Based Dairy Technologies among Smallholder Farmers in Ekerenyo Sub-County, Kenya. Asian Journal of Agricultural Extension, Economics \& Sociology, 16, 1-8. https://doi.org/10.9734/AJAEES/2017/32357

[24] Oywaya, M.A. (1995) Socio-Economic Factors Influencing Innovation and Participation of Women in Agricultural Extension Programmes in Malala Division of Machakos District, Kenya. Egerton University, Njoro, Kenya.

[25] Okuro, J.O., Murithi, F.M., Verkuijl, H., Mwangi, W., de Groote, H. and Macharia, G. (2002) Factors Affecting the Adoption of Maize Production Technologies in Embu District, Kenya. Proceedings of KARI Biennial Scientific Conference, 7, 45-55.

[26] Okuthe, I.K., Ngesa, F.U. and Ochola, W.O. (2007) Socio-Economic Determinants of Adoption of Improved Sorghum Varieties and Technologies among Smallholder Farmers in Western Kenya.

[27] Zamasiya, B., Nyikahadzoi, K. and Mukamuri, B.B. (2017) Factors Influencing Smallholder Farmers' Behavioural Intention towards Adaptation to Climate Change in Transitional Climatic Zones: A Case Study of Hwedza District in Zimbabwe. Journal of Environmental Management, 198, 233-239. https://doi.org/10.1016/j.jenvman.2017.04.073

[28] Tiyumtaba, S.M. (2016) Assessing Climate Change Adaptation Strategies Used by Smallholder Livestock Farmers in Upper West Region of Ghana. University of Ghana, Legon.

[29] Abayomi, S.O. (2013) Factors Explaining Dairy Cattle Adoption Behaviour among Smallholder Farmers in Kenya. Asian Journal of Animal and Veterinary Advances, 8, 893-903. https://doi.org/10.3923/ajava.2013.893.903

[30] Tegegne, F.S. (2017) Factors Affecting Adoption of Dairy Technologies and Their Impact on Farm Household Income and Asset Holdings: The Case of Tehuldedere District, South Wollo Zone, Amhara Region, Ethiopia. Hawassa University, Hawassa, Ethiopia.

[31] Hitayezu, P., Wale, E. and Ortmann, G. (2017) Assessing Farmers' Perceptions about Climate Change: A Double-Hurdle Approach. Climate Risk Management, 17, 123 138. https://doi.org/10.1016/j.crm.2017.07.001

[32] Ndiema, A.C. (2002) Factors Affecting the Adoption of Selected Wheat (Triticum aestivum) Production Technologies by Farmers in Njoro and Rongai Divisions of Nakuru District, Kenya. Egerton University, Njoro, Kenya.

[33] Seger, J. (2011) The New Digital [St]age: Barriers to the Adoption and Adaptation of New Technologies to Deliver Extension Programming and How to Address Them. Journal of Extension, 49, 1-6.

[34] Ntege-Nanyeenya, W., Mugisa-Mutetikka, M., Mwangi, W. and Verkuijl, H. (1997) An Assessment of Factors Affecting Adoption of Maize Production Technologies in Iganga District, Uganda. National Agricultural Research Organization (NARO) and International Maize and Wheat Improvement Center (CIMMYT), Addis Ababa, Ethiopia.

[35] Irungu, P.S., Mbogoh, S.G., Staal, S., Thorpe, W. and Njubi, D. (1998) Factors In- 
fluencing Adoption of Napier Grass in Smallholder Dairying in the Highlands of Kenya. Foods, Lands and Livelihoods: Setting Research Agendas for Animal Science. British Society of Animal Science. KARI, Nairobi, Kenya, 175-176.

[36] Wasula, S.L. (2000) Influence of Socio-Economic Factors on Adoption of Agroforestry Related Technology. The Case of Njoro and Rongai Districts, Kenya. Egerton University, Njoro, Kenya.

[37] Weinburg, B.A. (2004) Factors Affecting Adoption of Computer Technologies among Industrial Workers in America. (Excerpts from Galenson, D.W. and Weinburg, B.A. (2000) Age and the Quality of Work: The Case of Modern American Painters. Journal of Political Economy, 108, 761-777 and Galenson, D.W. and Weinburg, B.A. (2001) Creating Modern Art: The Changing Careers of Painters in France from Impressionism to Cubism. American Economic Review, 91, 1063-1071.)

[38] Akhter, A. and Olaf, E. (2016) Assessing Farmer Use of Climate Change Adaptation Practices and Impacts on Food Security and Poverty in Pakistan. Science Direct. Elsevier, Amsterdam.

[39] Muzamhindo, N., Mtabheni, S., Jiri, O., Mwakiwa, E. and Hanyani-Mlando, B. (2015) Factors Influencing Smallholder Farmers' Adaptation to Climate Change and Variability in Chiredzi District of Zimbabwe. Journal of Economics and Sustainable Development, 6, 1-9.

[40] Akinbami, C.A.O., Aluko, M.A.O. and Momodu, A.S. (2012) Technology Adoption and Women Entrepreneurial Behaviour: Case of Agri-Allied Businesses in Rural South Western Nigerian Communities. International Journal of Science and Technology, 1, 509-523.

[41] Muthui, M.M. (2015) Socio-Economic and Administrative Factors Influencing Adoption of Irrigation Technology in Tharaka Nithi County. University of Nairobi, Nairobi, Kenya.

[42] Atibioke, O.A., Ogunlade, I., Abiodum, A.A., Ogundele, B.A., Omodara, M.A. and Ade, A.R. (2012) Effects of Farmers' Demographic Factors on Adoption of Grain Storage Technologies Developed by Nigerian Stored Products Research Institute (NSPRI): A Case Study of Selected Villages in Ilorin West LGA of Kwara State. Research on Humanities at Social Sciences, 2, 56-65.

[43] Pooja, J. and Rekha, D. (2017) Impact of Demographic Factors: Technology Adoption in Agriculture. SCMS Journal of Indian Management, 93-102.

[44] Godoy, R., Franks, J.R. and Claudio, M.A. (1998) Adoption of Modern Agricultural Technologies by Lowland Indigenous Groups in Bolivia. The Role of Households, Villages, Ethnicity and Markets. Human Ecology, 26, 351-369.

https://doi.org/10.1023/A:1018779131004

[45] Wanyoike, F.N., Karugia, J.T. and Kimenye, L.N. (2002) A Gender Differentiated Analysis of Adoption of Improved Fodder Trees (Calliandra calothyrsus) by Smallholder Farmers in Embu District. Proceedings of KARI Biennial Scientific Conference, 7, 215-219.

[46] Dehinenet, G., Mekonnen, H., Kidoido, M., Ashenafi, M. and Guerne, E.B. (2014) Factors Influencing Adoption of Dairy Technology on Smallholder Dairy Farmers in Selected Zones of Amhara and Oromia National Regional States, Ethiopia. Discourse Journal of Agriculture and Food Sciences, 2, 126-135. 